\title{
Maternal obesity and postpartum haemorrhage after vaginal and caesarean delivery among nulliparous women at term: a retrospective cohort study
}

Elaine M Fyfe ${ }^{1 *}$, John MD Thompson², Ngaire H Anderson' ${ }^{1}$, Katie M Groom and Lesley M McCowan ${ }^{1}$

\begin{abstract}
Background: Increasing rates of postpartum haemorrhage in developed countries over the past two decades are not explained by corresponding changes in risk factors and conjecture has been raised that maternal obesity may be responsible. Few studies investigating risk factors for PPH have included BMI or investigated PPH risk among nulliparous women. The aim of this study was to determine in a cohort of nulliparous women delivering at term whether overweight and obesity are independent risk factors for major postpartum haemorrhage (PPH $\geq 1000 \mathrm{ml}$ ) after vaginal and caesarean section delivery.
\end{abstract}

Methods: The study population was nulliparous singleton pregnancies delivered at term at National Women's Hospital, Auckland, New Zealand from 2006 to 2009 (N=11,363). Multivariable logistic regression was adjusted for risk factors for major PPH.

Results: There were 7238 (63.7\%) women of normal BMI, 2631 (23.2\%) overweight and 1494 (13.1\%) obese. Overall, $\mathrm{PPH}$ rates were increased in overweight and obese compared with normal-weight women ( $\mathrm{n}=255$ [9.7\%], $\mathrm{n}=233$ $[15.6 \%]), n=524[7.2 \%], p<.001)$ respectively. There was an approximate twofold increase in risk in obese nulliparous women that was independent of confounders, adjusted odds ratio [aOR (95\% Cl)] for all deliveries 1.86 (1.51-2.28). Being obese was a risk factor for major PPH following both caesarean 1.73 (1.32-2.28) and vaginal delivery 2.11 (1.54-2.89) and the latter risk was similar after exclusion of women with major perineal trauma and retained placentae. Three additional factors were consistently associated with risk for major PPH regardless of mode of delivery: increasing infant birthweight, antepartum haemorrhage and Asian ethnicity.

Conclusion: Nulliparous obese women have a twofold increase in risk of major PPH compared to women with normal BMI regardless of mode of delivery. Higher rates of PPH among obese women are not attributable to their higher rates of caesarean delivery. Obesity is an important high risk factor for PPH, and the risk following vaginal delivery is emphasised. We recommend in addition to standard practice of active management of third stage of labour, there should be increased vigilance and preparation for PPH management in obese women.

Keywords: Nulliparity obesity postpartum haemorrhage

\footnotetext{
* Correspondence: e.fyfe@auckland.ac.nz

${ }^{1}$ Department of Obstetrics and Gynaecology, University of Auckland, Private Bag 92019, Auckland, New Zealand

Full list of author information is available at the end of the article
} 


\section{Background}

The incidence of postpartum haemorrhage (PPH) has been increasing in several developed countries over the past two decades, with rates rising by over one third [1-3]. This disturbing rise, with its associated maternal morbidity and mortality, [4] is not explained by corresponding changes in risk factors such as increased rates of caesarean section and induction of labour $[5,6]$. A contemporaneous rise in global obesity has raised conjecture that maternal obesity may be responsible for this increase in $\mathrm{PPH}$ rates [3]. Associations between obesity and PPH have been reported in several studies investigating the relationship between increased BMI and birth outcomes in a general obstetric population $[7,8]$. Studies investigating specific risk factors for $\mathrm{PPH}$ have demonstrated that nulliparous women have elevated rates of $\mathrm{PPH}$ compared to those who are multiparous [9-11]. Nulliparous women comprise a large sub-group of the birthing population especially in Western countries. Amongst studies specifically investigating a variety of risk factors for $\mathrm{PPH}$, maternal $\mathrm{BMI}$ is rarely considered as a potential risk factor. In these few studies, results are inconsistent with one showing no association between BMI and PPH [11], but others showing a positive association $[12,13]$. One study has directly investigated maternal BMI and risk of PPH, and in this group of women of mixed parity, increasing BMI was associated with increased risk of PPH [14].

Maternal obesity is associated with an elevated risk of intrapartum caesarean section, predominantly for failure to progress, [15-17] the mechanism of which is suggested to be due to reduced uterine contractility [17]. Among nulliparous women in labour at term, we have previously shown that the elevated risk of intrapartum caesarean is confined to the first stage of labour, as obese women who progress to the second stage of labour are just as likely to deliver vaginally as women with normal BMI [16]. We speculate therefore that obese women who give birth vaginally may have normal myometrial contractility. Uterine atony, the leading cause of $\mathrm{PPH}$, has been associated with slow progress in labour, a surrogate for impaired intrapartum myometrial contractility [11]. This has led us to hypothesise in this retrospective cohort study of nulliparous women who delivered at term, that 1 . overweight and obese women who delivered vaginally would not have increased rates of major PPH ( $\geq 1000 \mathrm{mls}$ ) compared to women with normal BMI, and 2. overweight and obesity would be independent risk factors for major PPH $(\geq 1000 \mathrm{mls})$ in women who had a caesarean section.

\section{Methods}

The National Women's Health (NWH) clinical database of births from Jan 2006 to Dec 2009 was used for this retrospective cohort study. NWH is a tertiary referral hospital in Auckland, New Zealand with a diverse ethnic population and approximately 7500 deliveries per year. The NWH database of births consists of de-identified, prospectively collected maternity data for all births occurring at greater than or equal to 20 weeks of gestation, which includes demographic data, antenatal complications, and detailed delivery and newborn data. Data are routinely checked for completeness, out of range values and inconsistency [18]. Ethical approval for this study was gained from the Northern X Regional Ethics Committee (NTX/09/179/EXP). The final study population included nulliparous women with a singleton pregnancy who delivered a live infant at term (Figure 1).

Maternal body mass index (BMI) $\left(\mathrm{kg} / \mathrm{m}^{2}\right)$ was calculated using maternal height and weight measured to the nearest centimetre and kilogram respectively at the first antenatal booking visit, and was available for $91.2 \%$ of the term study population. As the focus of the current study was overweight and obesity, underweight women (BMI less than 18.5), who comprised a small proportion of this population (6.0\%), were excluded. Women were classified into normal, overweight and obese groups according to conventional World Health Organization (WHO) BMI criteria: normal (18.5-24.9 kg/m²), overweight $\left(25-29.9 \mathrm{~kg} / \mathrm{m}^{2}\right)$, and obese $\left(\geq 30 \mathrm{~kg} / \mathrm{m}^{2}\right)$ [19]. Normal BMI was the referent group. The primary outcome measure was major primary postpartum haemorrhage defined as blood loss equal to or greater than

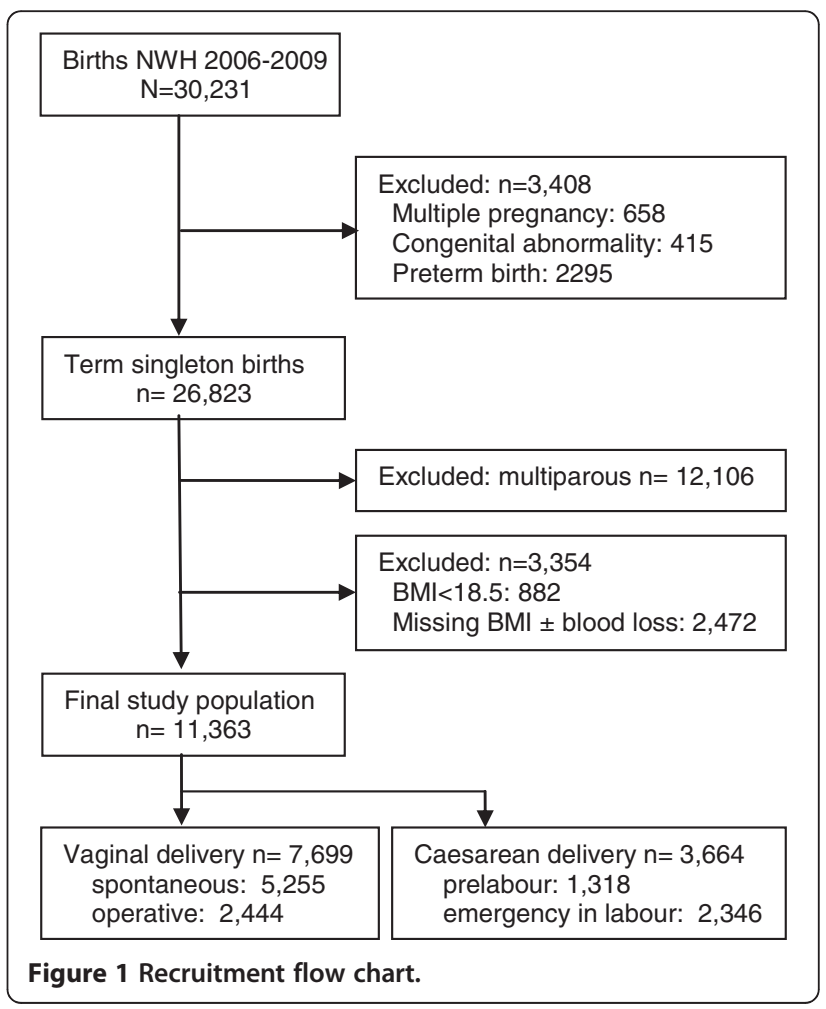


$1000 \mathrm{mls}$ [20] within $24 \mathrm{hrs}$ of delivery as recorded on the delivery summary by the attending midwife or doctor. Standard practice for estimation of blood loss is a combination of visualisation and measurement by weight. This clinically relevant amount was selected as a lesser blood loss of between $500 \mathrm{mls}$ and $1000 \mathrm{mls}$ is not uncommon and is not associated with adverse outcomes in the majority of healthy women [21,22]. Active management of the third stage of labour, 10IU of intramuscular oxytocin at the time of delivery of the anterior shoulder, is recommended standard practice within our unit. Estimated date of delivery (EDD) was calculated from a certain last menstrual period date or by ultrasound scan as per the Australasian Society for Ultrasound in Medicine guidelines [23,24]. Ethnicity was self-determined and prioritised as per New Zealand Ministry of Health guidelines [25]. Antepartum haemorrhage (APH) was defined as vaginal bleeding from any cause at or beyond 20 weeks of gestation after excluding placenta praevia [18]. Gestational hypertension and preeclampsia were defined as per International Society for the Study of Hypertension in Pregnancy criteria [26]. Gestational Diabetes Mellitus (GDM) was defined in accordance with The Australian Diabetes in Pregnancy Society [27].

Term delivery was delivery at a gestation of 37 weeks and 0 days or greater. Active labour was defined as regular, painful uterine contractions with progressive cervical effacement and dilation and cervical dilatation $\geq 3 \mathrm{~cm}$ [28]. Prelabour elective caesarean section delivery was a planned procedure before or following the onset of labour, when the decision for caesarean section was made before labour [29]. Prelabour emergency caesarean section delivery was a delivery required because of an emergency situation (e.g. fetal distress) before the onset of active labour when the caesarean section was performed having not been previously considered necessary. Emergency caesarean section in labour was delivery required because of an emergency situation in active labour (e.g. failure to progress, obstructed labour, fetal distress) when the caesarean section was performed having not been previously considered necessary [29]. Perineal tears were defined as per Royal College of Obstetricians and Gynaecologists [30]. Retained placenta was failure of placental delivery within 60 minutes after delivery of the fetus [31]. Small for gestational age (SGA) and large for gestational age (LGA) were defined as infant birthweight $<10^{\text {th }}$ and $>90^{\text {th }}$ customised centile respectively [32].

Univariable logistic regression was performed to compare maternal characteristics and antenatal, birth and neonatal outcomes for women who had major PPH compared with those who did not. This analysis was undertaken for all births and then repeated for vaginal and caesarean deliveries separately. Multivariable logistic regression for major $\mathrm{PPH}$ was performed adjusting for potential confounders identified after an extensive literature review. The following variables of hypothesised interest or potential confounders were hence included in the model: BMI, maternal age; ethnicity; smoking; maternity care provider; antepartum haemorrhage; diabetes; hypertension; induction of labour; epidural anesthesia; duration of first, second and third stages of labour; mode of delivery; perineal trauma; retained placenta and birthweight $[1,8,14,33,34]$. As all of the characteristics and outcomes in univariable analyses were potential confounders, all covariates were included in the multivariable models. Data analyses were performed using SAS ${ }^{\odot}$ version 9.2. (SAS Institute Inc., Cary, NC).

\section{Results}

Of 30,231 births at National Women's Hospital, Auckland, between January 2006 and December 2009, 12,407 (41\%) were in nulliparous women, of whom 11,363 (92\%) met the entry criteria for this study. Vaginal delivery occurred in $7699(67.8 \%)$, and caesarean section in $3664(32.2 \%)$ women (Figure 1). Prevalence of major postpartum haemorrhage (PPH) overall was 8.9\%, [vaginal delivery (5.4\%); caesarean section (16.2\%)]. Among the whole population, being overweight or obese was associated with an increased risk for PPH (OR 1.38, 95\% CI 1.18-1.61 and 2.37, 95\% CI 2.01-2.79 respectively). Other risk factors for $\mathrm{PPH}$ among all deliveries in univariable analysis were Pacific Island or Asian ethnicity, a history of antepartum haemorrhage $(\mathrm{APH})$ or hypertensive disorders, induction of labour and retained placenta (Table 1). Compared to spontaneous vaginal delivery, forceps and caesarean section were associated with a two to threefold increase in risk of major $\mathrm{PPH}$ respectively. Increasing infant birthweight also increased risk of major $\mathrm{PPH}$. After adjustment for confounding factors, there was a dose dependent relationship between BMI and risk of major $\mathrm{PPH}$, which was more common among women who were overweight $255(9.7 \%)$ or obese $233(15.6 \%)$ compared with those with normal BMI 524 (7.2\%), (aOR 1.20, 95\% CI 1.01-1.42 and 1.86, 95\% CI 1.51-2.28 respectively) (Figure 2). Other results were similar following adjustment for confounding factors.

Among women who delivered vaginally, independent risk factors were similar to those for the whole population (Table 2). Higher BMI was associated with an increased risk of major PPH (normal BMI 223 [4.4\%], overweight 96 [5.6\%], and obese 98 [10.5\%]). After adjustment for covariates, obese women had a twofold increase for major $\mathrm{PPH}$ compared to women with normal BMI [aOR 2.11, 95\% CI 1.54-2.89]. Other independent risk factors for major PPH in women with vaginal birth are shown in Table 2 . In subgroup analyses, women with risk factors associated with non-atonic PPH, namely episiotomy, third/ fourth degree perineal lacerations $(n=230)$ or retained placenta $(n=147)$ 
Table 1 Risk and protective factors for major postpartum haemorrhage ( $\geq 1000 \mathrm{mls})$ for term nulliparous women - all deliveries

\begin{tabular}{|c|c|c|c|c|}
\hline & No PPH & PPH & & \\
\hline & $n=10351(91.1 \%)$ & $n=1012(8.9 \%)$ & Unadjusted OR's & Adjusted OR's* \\
\hline \multicolumn{5}{|l|}{ Maternal characteristic } \\
\hline \multicolumn{5}{|l|}{$\mathrm{BMI}^{\dagger}$} \\
\hline $18.5-24.9$ & $6714(64.9)$ & $524(51.8)$ & 1.00 & 1.00 \\
\hline $25.0-29.9$ & $2376(22.9)$ & 255 & $1.38(1.18-1.61)$ & $1.20(1.01-1.42)$ \\
\hline$\geq 30.0$ & $1261(12.2)$ & $233(23.0)$ & $2.37(2.01-2.79)$ & $1.86(1.51-2.28)$ \\
\hline \multicolumn{5}{|l|}{ Age (y) } \\
\hline Less than 20 & $551(5.3)$ & $38(3.8)$ & $0.70(0.49-0.98)$ & $0.77(0.53-1.12)$ \\
\hline $20-29$ & 4078 (39.4) & $405(40.0)$ & 1.00 & 1.00 \\
\hline $30-34$ & $3553(34.3)$ & $336(33.2)$ & $0.95(0.82-1.11)$ & $0.94(0.79-1.11)$ \\
\hline$\geq 35$ & $2169(21.0)$ & $233(23.0)$ & $1.08(0.91-1.28)$ & $0.93(0.77-1.14)$ \\
\hline \multicolumn{5}{|l|}{ Ethnicity } \\
\hline European & $5573(53.9)$ & $491(48.5)$ & 1.00 & 1.00 \\
\hline Maori & 765 (7.4) & $78(7.7)$ & $1.16(0.90-1.49)$ & $1.27(0.95-1.69)$ \\
\hline Pacific island & $881(8.5)$ & $136(13.5)$ & $1.75(1.43-2.15)$ & $1.60(1.25-2.06)$ \\
\hline Asian & $2052(19.8)$ & $227(22.4)$ & $1.26(1.06-1.48)$ & $1.61(1.34-1.94)$ \\
\hline Indian & $766(7.4)$ & $64(6.3)$ & $0.95(0.72-1.24)$ & $1.20(0.89-1.61)$ \\
\hline Other & $314(3.0)$ & $16(1.6)$ & $0.58(0.35-0.96)$ & $0.68(0.40-1.15)$ \\
\hline \multicolumn{5}{|l|}{ Smoking (at booking) } \\
\hline No & $9086(87.8)$ & $908(89.7)$ & 1.00 & 1.00 \\
\hline Yes & $778(7.5)$ & $69(6.8)$ & $0.89(0.69-1.15)$ & $0.86(0.65-1.14)$ \\
\hline Unknown & $487(4.7)$ & $35(3.5)$ & $0.72(0.51-1.02)$ & $0.67(0.47-0.97)$ \\
\hline \multicolumn{5}{|l|}{ Maternity care } \\
\hline Private & $2556(24.7)$ & $231(22.8)$ & 1.00 & 1.00 \\
\hline Public & $7795(75.3)$ & $781(77.2)$ & $1.11(0.95-1.29)$ & $0.83(0.69-0.99)$ \\
\hline \multicolumn{5}{|l|}{ Pregnancy complications } \\
\hline \multicolumn{5}{|c|}{ Antepartum haemorrhage $^{\ddagger}$} \\
\hline No & 9899 (95.6) & $924(91.3)$ & 1.00 & 1.00 \\
\hline Yesł & $378(3.7)$ & $60(5.9)$ & $1.70(1.28-2.25)$ & $1.76(1.31-2.36)$ \\
\hline Placenta praevia & $74(0.7)$ & $28(2.8)$ & $4.06(2.61-6.30)$ & $4.00(2.48-6.47)$ \\
\hline \multicolumn{5}{|l|}{ Diabetes } \\
\hline $\mathrm{Nil}$ & 7651 (73.9) & $733(72.4)$ & 1.00 & 1.00 \\
\hline Type 1 or Type 2 & $64(0.6)$ & $8(0.8)$ & $1.31(0.62-2.73)$ & $0.82(0.38-1.80)$ \\
\hline Gestational & $463(4.5)$ & $52(5.2)$ & $1.17(0.87-1.58)$ & $0.92(0.66-1.29)$ \\
\hline Unknown & $2173(21.0)$ & $219(21.6)$ & $1.05(0.90-1.23)$ & $1.06(0.90-1.26)$ \\
\hline \multicolumn{5}{|l|}{ Hypertension } \\
\hline Nil & $9332(90.2)$ & $878(86.8)$ & 1.00 & 1.00 \\
\hline Chronic & $143(1.4)$ & $26(2.6)$ & $1.93(1.27-2.95)$ & $1.78(1.13-2.80)$ \\
\hline Gestational & $523(5.0)$ & $56(5.5)$ & $1.14(0.86-1.51)$ & $0.98(0.72-1.33)$ \\
\hline Preeclampsia & $353(3.4)$ & $52(5.1)$ & $1.57(1.16-2.11)$ & $1.33(0.95-1.85)$ \\
\hline Induction of labour & $3187(30.8)$ & $397(39.2)$ & $1.45(1.27-1.66)$ & $1.20(1.03-1.40)$ \\
\hline \multicolumn{5}{|l|}{ Delivery outcomes } \\
\hline \multicolumn{5}{|l|}{ Mode of delivery } \\
\hline \multicolumn{5}{|l|}{ Vaginal } \\
\hline Spontaneous & $5010(48.4)$ & $245(24.2)$ & 1.00 & 1.00 \\
\hline
\end{tabular}


Table 1 Risk and protective factors for major postpartum haemorrhage ( $\geq 1000 \mathrm{mls})$ for term nulliparous women - all deliveries (Continued)

\begin{tabular}{|c|c|c|c|c|}
\hline Ventouse & $1561(15.1)$ & $102(10.1)$ & $1.34(1.05-1.70)$ & $1.40(1.09-1.79)$ \\
\hline Forceps & $711(6.9)$ & $70(6.9)$ & $2.01(1.53-2.66)$ & $1.98(1.49-2.65)$ \\
\hline \multicolumn{5}{|l|}{ Caesarean } \\
\hline Prelabour & $1165(11.2)$ & $153(15.1)$ & $2.69(2.17-3.32)$ & $2.99(2.33-3.83)$ \\
\hline Emergency in labour & $1904(18.4)$ & $442(43.7)$ & $4.75(4.03-5.60)$ & $4.47(3.74-5.35)$ \\
\hline Retained placenta & $109(1.1)$ & $38(3.8)$ & $3.67(2.52-5.33)$ & $6.60(4.42-9.85)$ \\
\hline \multicolumn{5}{|l|}{ Neonatal outcomes } \\
\hline Gestation at delivery (days) & $278.7 \pm 8.6$ & $279.8 \pm 8.6$ & $1.11(1.05-1.17)$ per $\uparrow 1 w k$ & $0.96(0.90-1.03)$ per $\uparrow 1 w k$ \\
\hline Birthweight (g) & $3416 \pm 462$ & $3621 \pm 511$ & $1.58(1.47-1.69)$ per $\uparrow 500 \mathrm{~g}$ & $1.49(1.38-1.62)$ per $\uparrow 500 \mathrm{~g}$ \\
\hline Small for gestational age & $1205(11.6)$ & $84(8.3)$ & $0.69(0.55-0.87)$ & $\S$ \\
\hline Large for gestational age & $848(8.2)$ & $178(17.6)$ & $2.39(2.01-2.85)$ & $\S$ \\
\hline
\end{tabular}

Data are $\mathrm{n}(\%)$ or mean \pm standard deviation.

Significant adjusted OR's are bolded.

* Adjusted for all variables in table.

${ }^{\dagger}$ Body Mass Index.

${ }^{\ddagger}$ from any cause excluding placenta praevia >20wk gestation.

$\S \mathrm{SGA} / \mathrm{LGA}$ not included in multivariable model.

were excluded. The resulting independent risk factors were the same with a similar magnitude of effect (data not shown), demonstrating that the association between obesity and PPH was not attributable to perineal trauma or retained placenta.

Emergency caesarean section in labour was associated with a higher risk for major PPH compared with prelabour caesarean section (aOR 4.47, 95\% CI 3.74-5.35 versus aOR 2.99, 95\% CI 2.33-3.83) (Table 1). However, there was no significant difference in magnitude of effect related to any of the risk factors for major PPH between prelabour and emergency intrapartum caesarean section (data not shown). This demonstrated that the increase in risk with emergency intrapartum caesarean was not explained by any of the variables included in this study. Therefore, all caesarean sections were combined and analysed as a single entity (Table 3). Among women with caesarean sections, those who were obese had a near twofold increase in the rate of major $\mathrm{PPH}$ compared to women with normal BMI (normal [13.7\%], overweight [17.4\%], obese [24.2\%]) (Figure 2). This increase in risk associated with obesity was very similar following adjustment for covariates (aOR 1.73, 95\% CI 1.32-2.28), consistent with our findings after vaginal delivery (Table 3). Other independent risk factors for major PPH after caesarean section are shown in Table 3. Obesity was one of four factors (along with Asian ethnicity, antepartum haemorrhage and increasing infant birthweight) consistently associated with risk for major PPH regardless of mode of delivery. When we investigated the relationship between birthweight by z-scores (thus accounting for gestational age) and major PPH, we demonstrated a linear relationship between birthweight $\mathrm{z}$-scores and adjusted odds ratios of major PPH (data not shown).

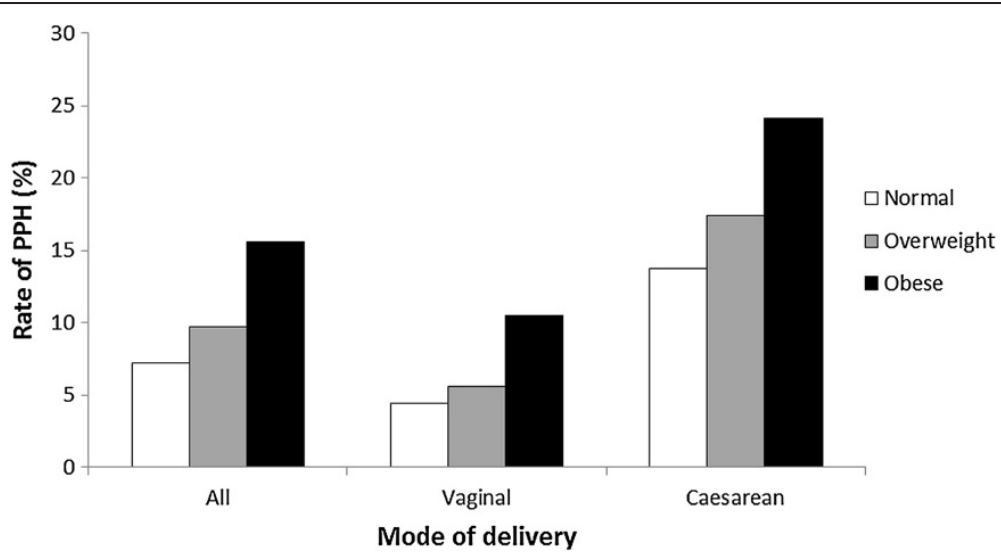

Figure 2 Rate of major PPH ( $\geq 1000 \mathrm{mls}$ ) by maternal BMI according to mode of delivery. 
Table 2 Independent risk factors for major postpartum haemorrhage $(\geq 1000 \mathrm{~m} / \mathrm{s})$ after vaginal delivery in term nulliparous women

\begin{tabular}{ll}
\hline Risk factor & Adjusted OR's* \\
\hline$B M I \geq 30.0$ & $2.11(1.54-2.89)$ \\
\hline Ethnicity & $2.30(1.62-3.27)$ \\
\hline Pacific island & $1.64(1.22-2.20)$ \\
\hline Asian & $1.91(1.25-2.91)$ \\
\hline Antepartum haemorrhage ${ }^{\dagger}$ & $1.97(1.22-3.19)$ \\
\hline Pre-eclampsia & $1.46(1.15-1.86)$ \\
\hline Induction of labour & $1.62(1.18-2.22)$ \\
\hline Third stage of labour $>15$ min $^{\ddagger}$ & $4.88(3.08-7.73)$ \\
\hline Retained placenta & $1.94(1.19-3.19)$ \\
\hline Episiotomy & $5.09(2.91-8.89)$ \\
\hline $3^{\text {rd }}$ or $4^{\text {th }}$ degree tear & $1.39(1.22-1.59)$ \\
\hline Birthweight $(\mathrm{g}) \uparrow 500 \mathrm{~g}$ &
\end{tabular}

Data are adjusted odds ratio (95\% confidence interval).

* Adjusted for all variables in Table 1 plus duration of $1^{\text {st }}, 2^{\text {nd }}$ and $3^{\text {rd }}$ stages of labour and perineal trauma (including graze, second degree tear).

${ }^{\dagger}$ from any cause excluding placenta praevia $>20 \mathrm{wk}$ gestation.

₹ compared with third stage 5-10 minutes.

\section{Discussion}

We have demonstrated that obese nulliparous women delivering a singleton infant at term have a twofold increase in risk of major PPH, regardless of mode of delivery, and that this risk is independent of many other recognised risk factors for major PPH. Contrary to our hypothesis we have found that obese nulliparous women who give birth vaginally have a twofold increase in risk of major $\mathrm{PPH}$, similar in magnitude to those delivering by caesarean section. Previous studies have suggested that the increase in risk of $\mathrm{PPH}$ in obese women was largely explained by a concurrent increased caesarean section rate $[35,36]$. Our findings identifying elevated risk for major PPH in obese women after vaginal birth are an important alert for clinicians. Active management of third stage is already recommended as standard

Table 3 Independent risk factors for major postpartum haemorrhage $(\geq 1000 \mathrm{mls})$ after caesarean delivery in term nulliparous women

\begin{tabular}{lc}
\hline Risk factor & Adjusted OR's* \\
\hline BMl $\geq 30.0$ & $1.73(1.32-2.28)$ \\
\hline Asian ethnicity & $1.57(1.23-2.01)$ \\
\hline Public obstetric care & $1.39(1.11-1.74)$ \\
\hline Antepartum haemorrhage $^{\dagger}$ & $1.65(1.08-2.52)$ \\
\hline Placenta praevia & $3.08(1.91-4.98)$ \\
\hline Chronic hypertension & $1.90(1.08-3.35)$ \\
\hline Birthweight $(\mathrm{g}) \uparrow 500 \mathrm{~g}$ & $1.48(1.34-1.64)$ \\
\hline
\end{tabular}

Data are adjusted odds ratio (95\% confidence interval).

* Adjusted for all variables in Table 1.

${ }^{\dagger}$ from any cause excluding placenta praevia $>20 w k$ gestation. practice for all women [37]. We would recommend in this group of women who are obese, additional vigilance is required to prevent and manage PPH. No other studies have primarily investigated the role of maternal obesity on risk of major PPH among nulliparous women. The rate of major PPH (greater than or equal to $1000 \mathrm{mls}$ ) in this nulliparous cohort was $8.9 \%$, (vaginal delivery [5.4\%]; caesarean section [16.2\%]). This is higher than the rate reported in a previous study in women of mixed parity (5.3\%) where a higher threshold was used for major PPH, namely blood loss greater than $1000 \mathrm{mls}$ [14]. If this same definition is applied to our population (i.e. $>1000 \mathrm{mls}$ ), the rates of major PPH are almost identical (5.1\% in our cohort). Among the few previous publications reporting maternal obesity and general birth outcomes in nulliparous women, comparisons are difficult due to absent or differing definitions of $\mathrm{PPH}$ and none have assessed the risk of PPH after vaginal delivery and caesarean section separately. Our findings are consistent with the only study of nulliparous women that adjusted for confounding factors, and reported a two fold increase in risk of major PPH in obese women [35]. However, in that study vaginal and caesarean births were not analysed separately, and no adjustment was made for perineal trauma or birthweight which are consistently reported as risk factors for PPH [34]. Two other studies in nulliparous women have reported no association between obesity and major PPH but these studies were underpowered [38,39]. In a further study, increased rates of PPH (blood loss greater than $500 \mathrm{mls}$ ) were reported after vaginal birth in nulliparous obese women compared to those with a BMI of 20-30, but the magnitude of risk was not quantified [40].

Only one other study has primarily investigated the relationship between maternal obesity and PPH (defined as haemorrhage $>1000 \mathrm{mls}$ ) [14]. Blomberg reported a small increased risk among obese women following vaginal delivery, but PPH risk was variable according to class of obesity following caesarean section. This study population was of mixed parity, and adjustment was only possible for very limited confounders (year of infant birth, maternal age, parity and smoking). Blomberg reported an increased rate of PPH in obese women predominantly associated with uterine atony, but also due to soft tissue trauma. No association was reported between obesity and PPH due to retained placenta. Although we did not have data available to identify the primary cause of $\mathrm{PPH}$, when we performed a subgroup analysis amongst women who delivered vaginally excluding those with major perineal trauma (episiotomy or third/fourth degree laceration), and/or retained placenta, there was no significant difference in effect. We therefore demonstrated that the higher rates of $\mathrm{PPH}$ in obese women in our study were not attributable to either major perineal 
trauma or retained placenta and hence were most likely due to uterine atony. Other risk factors we found for major PPH after vaginal birth were similar to those previously identified, as seen in Table 2 .

It is well established that obese women have higher rates of caesarean section, especially emergency intrapartum caesarean section, [16] and we confirmed that this mode of delivery was associated with the highest rates of PPH among the whole study population. We found that obese women who had a caesarean section had a $70 \%$ increase in risk for PPH. Challenging surgery in obese patients is associated with prolonged operative time, and consequently with increased blood loss [41]. Other risk factors that we identified for PPH after caesarean section are consistent with previous studies [5,33,41-43].

Obesity was one of four factors we identified that independently increased risk for PPH after both vaginal and caesarean deliveries among nulliparous women (along with increasing birthweight, APH and Asian ethnicity). The relevance of our finding that increasing birthweight is associated with risk of $\mathrm{PPH}$ is that we have shown that the relationship is dose dependent and that there is not a cut off at which increased risk occurs, for example with macrosomic or large for gestational age infants, which has been reported previously $[44,45]$. Contextualising this finding to the clinical setting, there is a $40 \%$ increase in risk for PPH with every $500 \mathrm{~g}$ increase in birthweight in term infants.

Our novel finding that the independent risk for $\mathrm{PPH}$ was increased in women with a history of APH from any cause exclusive of placenta praevia is clinically significant as APH (predominantly of unknown origin) occurred in $5.2 \%$ of our nulliparous cohort. An association between PPH and Asian ethnicity has been reported previously $[34,45,46]$.

A strength of our study was the ability to adjust for many known risk factors for PPH to better determine the independent effect of obesity for vaginal and caesarean delivery discretely. In keeping with other clinical studies, visual estimation was usual practice to estimate blood loss in our study [34]. Visual estimation has been reported to underestimate higher volumes of blood loss, [47] it is therefore unlikely that we overestimated major $\mathrm{PPH}$ prevalence. We did not have data to further assess PPH defined by peripartum reduction in haemoglobin or requirement for blood transfusion.

\section{Conclusions}

We advocate the inclusion of obesity in future research investigating risk factors for major $\mathrm{PPH}$ as recommended by the International Postpartum Hemorrhage Collaborative Group [3]. Nulliparous obese women should be regarded as high risk for PPH, with a twofold increase in risk of major PPH $(\geq 1000 \mathrm{mls})$ compared to normal weight women regardless of mode of delivery. Therefore we recommend in addition to standard practice of active management of third stage of labour, there should be increased vigilance and preparation for $\mathrm{PPH}$ management in obese women.

\section{Details of ethics approval}

Ethical approval for this study was gained from the Northern X Regional Ethics Committee (NTX/09/179/ EXP).

\section{Competing interests}

The authors declare that they have no competing interests.

\section{Authors' contributions}

EF conceived of the study and participated in its design, performed the statistical analysis, interpreted the data and drafted and revised the manuscript. LMCC conceived of the study and participated in its design, interpreted the data and helped to draft and revise the manuscript. JT performed the statistical analysis, interpreted the data, and helped to draft and revise the manuscript. NA interpreted the data and helped to draft and revise the manuscript. KG interpreted the data and helped to draft and revise the manuscript. All authors read and approved the final manuscript.

\section{Acknowledgements \\ Nil \\ Source of funding \\ University of Auckland Senior Health Research Scholarship}

\section{Author details}

'Department of Obstetrics and Gynaecology, University of Auckland, Private Bag 92019, Auckland, New Zealand. ²Department of Paediatrics, University of Auckland, Private Bag 92019, Auckland, New Zealand.

Received: 2 August 2012 Accepted: 16 October 2012

Published: 18 October 2012

\section{References}

1. Rossen J, Okland I, Nilsen OB, Eggebo TM: Is there an increase of postpartum hemorrhage, and is severe hemorrhage associated with more frequent use of obstetric interventions? Acta Obstet Gynecol Scand 2010, 89(10):1248-1255.

2. Callaghan WM, Kuklina EV, Berg CJ: Trends in postpartum hemorrhage: United States, 1994-2006. Am J Obstet Gynecol 2010, 202(4):353. e351-356.

3. Knight M, Callaghan WM, Berg C, Alexander S, Bouvier-Colle M-H, Ford JB, Joseph K, Lewis G, Liston RM, Roberts CL, et al: Trends in postpartum hemorrhage in high resource countries: a review and recommendations from the International Postpartum Hemorrhage Collaborative Group. BMC Pregnancy Childbirth 2009, 9:55.

4. (CMACE) CFMaCE: Maternal obesity in the UK: Findings from a national project. London: CMACE; 2010.

5. Ford JB, Roberts CL, Simpson JM, Vaughan J, Cameron CA: Increased postpartum hemorrhage rates in Australia. Int J Gynaecol Obstet 2007, 98(3):237-243.

6. Joseph KS, Rouleau J, Kramer MS, Young DC, Liston RM, Baskett TF, Maternal Health Study Group of the Canadian Perinatal Surveillance S: Investigation of an increase in postpartum haemorrhage in Canada. BJOG 2007, 114(6):751-759.

7. Heslehurst N, Simpson H, Ells LJ, Rankin J, Wilkinson J, Lang R, Brown TJ, Summerbell CD: The impact of maternal BMI status on pregnancy outcomes with immediate short-term obstetric resource implications: a meta-analysis. Obes Rev 2008, 9(6):635-683.

8. Sebire NJ, Jolly M, Harris JP, Wadsworth J, Joffe M, Beard RW, Regan L, Robinson S: Maternal obesity and pregnancy outcome: a study of 287,213 pregnancies in London. Int J Obes Relat Metab Disord 2001, 25(8):1175-1182. 
9. Magann EF, Doherty DA, Briery CM, Niederhauser A, Chauhan SP, Morrison JC Obstetric characteristics for a prolonged third stage of labor and risk for postpartum hemorrhage. Gynecol Obstet Invest 2008, 65(3):201-205.

10. Combs CA, Murphy EL, Laros RK Jr: Factors associated with postpartum hemorrhage with vaginal birth. Obstet Gynecol 1991, 77(1):69-76.

11. Driessen M, Bouvier-Colle M-H, Dupont C, Khoshnood B, Rudigoz R-C, Deneux-Tharaux C, Pithagore G: Postpartum hemorrhage resulting from uterine atony after vaginal delivery: factors associated with severity. Obstet Gynecol 2011, 117(1):21-31.

12. Naef RW 3rd, Chauhan SP, Chevalier SP, Roberts WE, Meydrech EF, Morrison JC: Prediction of hemorrhage at cesarean delivery. Obstet Gynecol 1994, 83(6):923-926.

13. Stones RW, Paterson CM, Saunders NJ: Risk factors for major obstetric haemorrhage. Eur J Obstet Gynecol Reprod Biol 1993, 48(1):15-18.

14. Blomberg M: Maternal obesity and risk of postpartum hemorrhage. Obstet Gynecol 2011, 118(3):561-568.

15. Bergholt T, Lim LK, Jorgensen JS, Robson MS: Maternal body mass index in the first trimester and risk of cesarean delivery in nulliparous women in spontaneous labor. Am J Obstet Gynecol 2007, 196(2):163. e161-165.

16. Fyfe E, Anderson N, North R, Chan E, Taylor R, Dekker G, McCowan L: Risk of First-Stage and Second-Stage Cesarean Delivery by Maternal Body Mass Index Among Nulliparous Women in Labor at Term. Obstet Gynecol 2011 117(6):1315-1322

17. Zhang J, Bricker L, Wray S, Quenby S: Poor uterine contractility in obese women.[see comment]. BJOG 2007, 114(3):343-348.

18. Raja UA, McAree T, Bassett $P$, Sharma $S$ : The implications of a raised maternal BMI: a DGH experience. J Obstet Gynaecol 2012, 32(3):247-251.

19. Global Database on Body Mass Index: BMI Classification. http://apps.who.int/ bmi/index.jsp?introPage=intro 3.html.

20. Women's Hospitals Australasia: Supporting Excellence in Maternity Care: The Core Maternity Indicators Project. Turner, Australian Capital Territory: Women's Hospitals Australasia; 2007.

21. Gilstrap ILC, Ramin SM: Postpartum hemorrhage. Clin Obstet Gynecol 1994 37(4):824-830.

22. Drife J: Management of primary postpartum haemorrhage. $\mathrm{Br} J$ Obstet Gynaecol 1997, 104:275-277.

23. Australasian Society for Ultrasound in Medicine: Statement on normal ultrasonic fetal measurements. In: Policies and Statements D7. 2007. http://www.asum.com.au/site/policies.php: ASUM; 2001-2007.

24. Australasian Society for Ultrasound in Medicine: Guidelines for the mid trimester obstetric scan. In Policies and Statements D2. 2007. http://www. asum.com.au/site/policies.php: ASUM; 2001-2007.

25. Ministry of Health: Ethnicity Data Protocols for the Health and Disability Sector. Wellington: Ministry of Health; 2004.

26. Brown MA, Hague WM, Higgins J, Lowe S, McCowan L, Oats J, Peek MJ, Rowan JA, Walters BN, Austalasian Society of the Study of Hypertension in $P$ : The detection, investigation and management of hypertension in pregnancy: full consensus statement. Aust N Z J Obstet Gynaecol 2000, 40(2):139-155

27. Hoffman L, Nolan C, Wilson JD, Oats JJ, Simmons D: Gestational diabetes mellitus--management guidelines. The Australasian Diabetes in Pregnancy Society (updated Dec 2002). Med J Aust 1998, 169(2):93-97.

28. Chamberlain G: Turnbull's Obstetrics. 2nd edition. Edinburgh: Churchill Livingstone; 1995.

29. National Centre for Classification in Health (Sydney): Australian Coding Standards for ICD-10_AM, Volume 5. 4th edition. Sydney: National Centre for Classification in Health; 2004.

30. Fernando RJ, Williams AA, Adams EJ: The Management of Third and Fourth Degree Tears. In vol. Green-top Guideline No. 29, 2007 edn.: Royal College of Obstetricians and Gynaecologists; 2007.

31. ADHB Policies and Procedures. http://adhbintranet/ ADHB_Policies_and_Procedures/Clinical/National_Women's/Maternity/ retained_placenta.htm

32. McCowan LM, Stewart AW, Francis A, Gardosi J: A customised birthweight centile calculator developed for a New Zealand population. Aust N Z J Obstet Gynaecol 2004, 44(5):428-431.

33. Bateman BT, Berman MF, Riley LE, Leffert LR: The epidemiology of postpartum hemorrhage in a large, nationwide sample of deliveries. Anesth Analg 2010, 110(5):1368-1373.

34. Al-Zirqi I, Vangen S, Forsen L, Stray-Pedersen B: Prevalence and risk factors of severe obstetric haemorrhage. BJOG 2008, 115(10):1265-1272.
35. Bhattacharya S, Campbell DM, Liston WA, Bhattacharya S: Effect of Body Mass Index on pregnancy outcomes in nulliparous women delivering singleton babies. BMC Publ Health 2007, 7:168.

36. Mantakas A, Farrell T: The influence of increasing BMI in nulliparous women on pregnancy outcome. Eur J Obstet Gynecol Reprod Biol 2010, 153(1):43-46.

37. World Health Organisation (2012). WHO recommendations for the prevention and treatment of postpartum haemorrhage. World Health Organisation. Italy, World Health Organisation; 2012.

38. Athukorala C, Rumbold AR, Willson KJ, Crowther CA: The risk of adverse pregnancy outcomes in women who are overweight or obese. BMC Pregnancy Childbirth 2010, 10:56

39. Haeri S, Guichard I, Baker AM, Saddlemire S, Boggess KA: The effect of teenage maternal obesity on perinatal outcomes. Obstet Gynecol 2009, 113(2 Pt 1):300-304.

40. Usha Kiran TS, Hemmadi S, Bethel J, Evans J: Outcome of pregnancy in a woman with an increased body mass index. BJOG 2005, 112(6):768-772.

41. Doherty DA, Magann EF, Chauhan SP, O'Boyle AL, Busch JM, Morrison JC: Factors affecting caesarean operative time and the effect of operative time on pregnancy outcomes. Aust N Z J Obstet Gynaecol 2008, 48(3):286-291.

42. Sheiner E, Sarid L, Levy A, Seidman DS, Hallak M: Obstetric risk factors and outcome of pregnancies complicated with early postpartum hemorrhage: a population-based study. J Matern Fetal Neonatal Med 2005, 18(3):149-154

43. Magann EF, Evans S, Hutchinson M, Collins R, Lanneau G, Morrison JC: Postpartum hemorrhage after cesarean delivery: An analysis of risk factors. South Med J 2005, 98(7):681-685.

44. Bais JMJ, Eskes M, Pel M, Bonsel GJ, Bleker OP: Postpartum haemorrhage in nulliparous women: incidence and risk factors in low and high risk women. A Dutch population-based cohort study on standard ( $>$ or $=$ $500 \mathrm{ml}$ ) and severe (> or $=1000 \mathrm{ml}$ ) postpartum haemorrhage. Eur J Obstet Gynecol Reprod Biol 2004, 115(2):166-172.

45. Magann EF, Evans S, Hutchinson M, Collins R, Howard BC, Morrison JC: Postpartum hemorrhage after vaginal birth: an analysis of risk factors. South Med J 2005, 98(4):419-422.

46. Combs CA, Murphy EL, Laros RK Jr: Factors associated with hemorrhage in cesarean deliveries. Obstet Gynecol 1991, 77(1):77-82.

47. Duthie S, Ven D, Yung G, Guang D, Chan S, Ma H-K: Discrepancy between laboratory determination and visual estimation of blood loss during normal delivery. Eur J Obstet Gynecol Reprod Biol 1990, 38:119-124.

\section{doi:10.1186/1471-2393-12-112}

Cite this article as: Fyfe et al:: Maternal obesity and postpartum haemorrhage after vaginal and caesarean delivery among nulliparous women at term: a retrospective cohort study. BMC Pregnancy and Childbirth 2012 12:112.

\section{Submit your next manuscript to BioMed Central and take full advantage of:}

- Convenient online submission

- Thorough peer review

- No space constraints or color figure charges

- Immediate publication on acceptance

- Inclusion in PubMed, CAS, Scopus and Google Scholar

- Research which is freely available for redistribution 